\title{
CORPOS E CENÁRIOS (RE)TRADUZIDOS EM HABIBI, DE CRAIG THOMPSON: TRANSCULTURALIDADE E ORIENTALISMO REVISTOS
}

\author{
BODIES AND SCENES (RE)TRANSLATED IN HABIBI, \\ BY CRAIG THOMPSON: TRANSCULTURALITY AND \\ ORIENTALISM REVIEWED
}

\section{Adriano Clayton da Silva*}

\begin{abstract}
RESUMO
Neste trabalho, apresento e discuto a transculturalidade, as imagens e a tradução na grapbic novel Habibi (2011), de Craig Thompson, buscando mostrar como tal obra é uma tradução transcultural, já que se propõe a representar um mundo árabe oriental para olhos ocidentais, mas incorrendo no mesmo orientalismo institucionalizado que permeia diversas outras obras de arte, científicas e políticas do mundo ocidental, as quais tendem a diminuir e a homogeneizar as diversas culturas dos povos habitantes do que se chama atualmente Oriente Médio. No caso de Habibi, é pelos corpos e cenários que o orientalismo mais se faz presente, evocando a velha fórmula das mil e uma noites enquanto conta sua história como se todos os povos do Oriente Médio vivessem no deserto usando turbantes, entre outros estereótipos. Ao final, apresento uma possibilidade de tradução através das imagens da grapbic novel, de modo a tentar diminuir, ao menos um pouco, a influência do orientalismo enviesado em Habibi.
\end{abstract}

Palavras-chave: transculturalidade; orientalismo; Habibi.

\section{ABSTRACT}

In this work, I present and discuss transculturalism, images and translation in Craig Thompson's graphic novel Habibi, trying to show how this work is a transcultural translation, since it aims to represent an Eastern Arab world to Western eyes, but incurring the same institutionalized orientalism that embodies several other works of art, science and politics in the Western world, which tend to diminish and homogenize the diverse cultures of the peoples living in what is now called the Middle East. In Habibi's case, it is through bodies and scenes that orientalism is most present, evoking the old formula of the Arabian Nights while telling its story - as if all the peoples of the Middle East lived in the desert wearing turbans, among other stereotypes. In the end, I present a possibility of translation through the images of the graphic novel, in order to try to diminish, at least a little, the influence of the biased orientalism in Habibi.

Keywords: transculturality; orientalism; Habibi.

\footnotetext{
* Instituto Federal de Educação, Ciência e Tecnologia do Sul de Minas Gerais, IFSULDEMINAS, Machado, MG, Brasil. drianovsk@gmail.com

Orcid: https://orcid.org/0000-0002-6556-884X
} 
Quando traduzo, penso que estou dando voz, e principalmente estou dando voz a quem normalmente não a tem, um pouco pela minha formação, de gostar de estar ao lado dos perdedores ou minorias. Não sei, talvez por isso eu escolho uma língua menos popular. Se não se tomar cuidado, pode-se causar danos, e não falo de danos "literários". Se estragarmos uma obra prima, ok, estragamos uma obra prima, mas não estragamos apenas uma obra prima, estragamos a percepção de um mundo inteiro. ${ }^{1}$

Elisabetta Bartuli - Tradurre (2008)

\section{INTRODUÇÃO}

Já faz um tempo que os estudos culturais e áreas afins começaram a entender as pessoas - dentro de determinada sociedade e/ou cultura - como sujeitos transculturais. Expostas desde muito pequenas a cenários, línguas e corpos tanto próximos - contextos familiares - quanto distantes - vizinhanças e cotidianos fora de casa, tais pessoas são atravessadas por todo tipo de signo, verbal, visual, sonoro, etc., e sua respectiva semiose.

Também a tradução - seja esta de palavras ou outros signos - e as imagens trabalham como agentes transculturais. A tradução é um fenômeno intrinsecamente transcultural, já que significa entrelaçamento e imbricação de duas ou mais línguas/ culturas, que se movimentam no mesmo tempo e espaço que é o agente tradutor. Já as imagens - e aqui meu foco é nas estáticas - têm um papel fundamental na transmissão e construção de percepções de mundo, mas, tal como as palavras, são também filtradas e enviesadas por preconceitos e estereótipos.

Os quadrinhos, enquanto narrativas gráficas com poder de representar corpos e cenários transculturais, sofrem e reproduzem ideologias que nem sempre beneficiam as pessoas e culturas ali representadas. É o caso, por exemplo, da grapbic novel Habibi, de Craig Thompson (2011a), que busca representar de forma simplificada e redutora os complexos e diferentes mundos do Oriente Médio - e me refiro não apenas a culturas, mas também a aspectos socioeconômicos, geográficos e históricos.

Neste trabalho, apresento e discuto a transculturalidade, as imagens e a tradução do mundo dito oriental em Habibi, de forma a mostrar como tal obra é uma tradução transcultural, já que se propõe a representar corpos e cenários de

1. "Quando traduco penso che sto dando voce, e in più delle volte sto dando voce a chi normalmente non ce l'ha, un po' per conformazione mia a me piace stare dalla parte dei perdenti, o delle minoranze, non lo so forse per questo, per questo ho scelto una língua chi è meno gettonata, se non si fa attenzione, si fanno danni... e non parlo di danni letterari... Abbiamo rovinato un capolavoro, va bene abbiamo rovinato un capolavoro, ma non abbiamo rovinato solo un capolavoro, abbiamo rovinato la percezione di un mondo intero!" (Tradução minha - todas as traduções não referenciadas são de minha autoria) Elisabetta Bartuli é tradutora do árabe para o italiano. 
um mundo árabe oriental para olhos ocidentais, embora repetindo o orientalismo institucionalizado que aparece em diversas outras obras de arte, científicas e políticas, as quais tendem a diminuir e a homogeneizar as diversas culturas dos povos habitantes do que se chama atualmente Oriente Médio. Por fim, apresento uma possibilidade de, ao menos em parte, reinventar esse Oriente que permeia Habibi.

\section{TRANSCULTURAL OU MESTIÇO?}

Para falar de transculturalidade recorro à ideia já consagrada do filósofo Wolfgang Welsch (2010): somos seres essencialmente culturais, tanto no sentido de nossas práticas cotidianas e individuais, que guiam a forma como interagimos com o mundo e as pessoas à nossa volta, quanto no sentido geográfico e sociopolítico, já que cada um de nós "pertence" a um determinado lugar no mundo, dentro de uma certa nação e cultura. Essas duas instâncias de cultura, individual e social, não são, contudo, monolíticas, no sentido de que nossos referenciais culturais provenham apenas de um ponto e sociedade no mundo. Muito pelo contrário, somos seres permanentemente atravessados e influenciados por diversas expressões e percepções de mundo, cada uma carregando determinada visão e formação cultural. Ao mesmo tempo, deixamos transparecer nossas percepções e, assim, influenciamos também outras pessoas de outras culturas. A transculturalidade é fundamental para que possamos repensar ideias como homogeneidade de cultura e separatismos, que pregam ser possível algum tipo de pureza ou exclusividade de um povo.

Mas ser transcultural de modo algum implica perder a individualidade, e isso é fácil de se perceber: como cada pessoa está localizada num determinado lugar, interagindo de determinadas formas e experimentando o mundo exclusivamente com seu próprio corpo - o que implica potencialidades e limitações -, a mistura transcultural jamais será igual de pessoa para pessoa.

Importante trazer a questão do corpo. Sônia Maluf (2001, p. 95-96) fala da relação entre o sujeito e seu corpo, mostrando que tatuagens ou piercings não são apenas inscrições de alguns símbolos ou valores num pedaço de carne. A tatuagem ou o piercing também trabalharão na constituição de um determinado tipo de sujeito, havendo assim, na corporalidade, a construção da pessoa. Portanto, o corpo depende sim de nossas ideias e culturas e vice-versa, ao mesmo tempo em que a interação com outros corpos, reais ou representados em fotos, desenhos, etc., levarão a outras formas de perceber o outro. É claro que isso vale também para as roupas que esses corpos usam. Guardemos essa ideia de corpo por enquanto. 
Outro aspecto importante a problematizar é essa individualidade transcultural. Zygmunt Bauman (2001, p. 39) fala do excesso de individualismo em nossa época e de suas consequências para a sociedade e para a cidadania:

A sociedade moderna existe em sua atividade incessante de "individualização", assim como as atividades dos indivíduos consistem na reformulação e renegociação diárias da rede de entrelaçamentos chamada "sociedade". Nenhum dos dois parceiros fica parado muito tempo. E assim o significado da "individualização" muda, assumindo sempre novas formas...

Para Bauman, os motivos dessa individualização estão essencialmente ligados à forma como a cultura neoliberalista transformou-se nas últimas décadas. Temos identidades fluidas, de acordo com a conveniência, mas também voláteis e imediatistas. $\mathrm{O}$ consumismo exagerado também traz como consequência uma falta de apego das pessoas a qualquer tipo de relação duradoura. Mas, mais do que não querer relações duradouras, as pessoas não conseguem nem conceber o que seja isso. Fica complicado, portanto, dizer que ser transcultural implique uma visão menos preconceituosa das relações humanas, como deseja Welsch. Ou talvez seja apenas a falta dessa consciência transcultural na maioria das pessoas.

É preciso também refletir melhor sobre a própria ideia de transculturalidade. Como Welsch (2010) aponta, é um conceito mais adequado para explicar a identidade das pessoas do que a interculturalidade ou a multiculturalidade, já que estas últimas ainda trabalham com a noção de culturas como ilhas ou esferas separadas umas das outras. Contudo, as ideias de Welsch foram inicialmente escritas em alemão para um público europeu. Por que isso é importante? Porque devemos lembrar que a História da Europa, antiga e recente, tem mostrado como certos encontros de culturas e tentativas de mistura não têm sido muito bem aceitos por parte significativa de europeus. Jan Blommaert e Jef Verschueren (2002) mostram como muitos grupos políticos de direita europeus apresentam em seus discursos algo que os dois linguistas nomeiam homogenismo (bomogeneism no original): o migrante estrangeiro - e com isso referindo-se a qualquer um que venha de fora da Europa Ocidental - é até tolerado, desde que não seja tão diferente a ponto de chocar ou incomodar, e desde que não seja tão numeroso a ponto de representar uma ameaça ao estilo de vida dos nativos com quem ele decide conviver. ${ }^{2}$

Assim, a transculturalidade de Welsch poderia ser um eufemismo europeu para evitar falar diretamente de hibridismo, de mistura de raças, de pessoas que podem ser formadas e construídas pelo encontro e cruzamento de culturas, línguas

2. A mesma ideia de homogenismo parece caber muito bem aos migrantes latinos na América do Norte. 
e mesmo corpos muito distintos em suas origens. É um atravessamento de culturas, desde que dentro da Europa e, portanto, longe de eventuais "impurezas externas".

Contraponto a transculturalidade, François Laplantine e Alexis Nouss (1997) evocam a ideia de mestiçagem para explicar o atravessamento de culturas e línguas no corpo individual. Não existe uma origem, uma fundação pré-determinada no pensamento mestiço, nem há uma separação de qualquer tipo, nenhuma dualidade permanente que faça com que o mestiço, seja na língua, seja na cultura, seja no corpo, consiga determinar se uma ou outra parte de sua formação está dominante durante alguma reação a qualquer fato ou situação do mundo. $O$ mestiço de Nouss e Laplantine é e permanece mestiço, independentemente do lugar em que tenha nascido ou que venha a viver em qualquer momento de sua vida. É como o sim nietzschiano à vida, abraçando e superando todas as formas decadentes de dualismo, niilismo e oposição de forças de Hegel e de outros pensadores europeus. Por fim, o mestiço parece muito mais consciente de sua condição de híbrido, ao mesmo tempo em que se mantém num devir constante, mas sempre equilibrando os elementos culturais, de modo que nenhum se sobressaia aos demais. Ele deu um passo além do transcultural de Welsch. Talvez a própria palavra - mestiço - o obrigue a constantemente rever sua posição no mundo. ${ }^{3}$

Em alguns casos, porém, a situação de mestiçagem condiciona a vida da pessoa, independentemente de sua consciência ou vontade. É o caso dos migrantes e exilados. Sobre os primeiros, Fernando Toledo (2015) nos traz o exemplo de Rafik Schami, um escritor sírio radicado na Alemanha, e sua literatura de imigrante. Toledo mostra que a condição de migrante permeia toda a obra de Schami, que escreve em alemão sobre sua infância em Damasco, onde viveu em um ambiente pluricultural em termos de costumes, nacionalidades e religiões.

Sobre os exilados, Edward Said (2003a) nos lembra que durante o século $\mathrm{XX}$, devido às guerras e a movimentos políticos hostis a qualquer forma de protesto, o número de exilados cresceu assustadoramente. Mas o exilado carrega seu nacionalismo consigo, o que o torna ressentido na nova terra, mesmo que esta se ofereça - em alguns casos - generosamente a ele. Contudo, esse ressentimento, aliado ao fato de que aprende a viver com muito pouco em termos materiais - ele não sabe se e quando precisará exilar-se novamente -, acaba por fazer do exilado

\footnotetext{
3. Mudança de terminologia é um dos recursos mais comuns quando se trata de (des)valorizar algo ou alguém. É como a discussão entre o que é ser imigrante e o que é ser expatriado na Europa. Kieran Nash (2017) explica muito bem que essa é tão somente uma questão de semântica, já que em ambos os casos trata-se de pessoas que buscam melhores condições de vida no estrangeiro. Para não serem comparados ao migrante pardo ou negro e pobre, os europeus brancos e com dinheiro acharam uma palavra para definirem a si próprios.
} 
uma pessoa experta e prática em certos assuntos: "não surpreende que tantos exilados sejam romancistas, jogadores de xadrez, ativistas políticos e intelectuais. Essas ocupações exigem um investimento mínimo em objetos e dão um grande valor à mobilidade e à perícia" (SAID, 2003a, p. 54).

O imigrante, exilado ou não, está muito mais consciente de seu devir conforme a cultura/língua/lugar em que esteja. Ele é a tradução transcultural. Mas podemos dizer que quanto mais aceita sua condição, mais mestiço e consciente se torna. Ao mesmo tempo, forças estrangeirizantes e domesticantes agem nessa pessoa imigrante. Ela busca se domesticar nos novos cenários da terra alheia, devindo uma nova entidade. Se essa domesticação será percebida e bem recebida pelo outro, pelos nativos da terra, só o tempo dirá, a depender muito mais da vontade do nativo em aceitar ou não aquela tradução que se mostra em carne e osso à sua frente.

\section{TRADUÇÃO E IMAGENS COMO TRANSCULTURAIS}

Em outro de seus escritos, Laplantine (2005) discute a "dor" do binarismo na tradução: enquanto entidades separadas, as línguas sofrem com oposições e equivalências forçadas. Contudo, no momento em que se consideram as línguas como partes de um todo, tudo o que o tradutor deve fazer é trabalhar nos interstícios entre elas, nos pequenos espaços de diferença. E essa diferença não é mais entre duas entidades absurdamente diferentes, mas apenas entre dois elementos que convivem no mesmo corpo e não sabiam disso. Alexis Nouss (2012), também em outro texto, concorda com isso ao dizer que as línguas na tradução devem ser encaradas como dois territórios móveis que se combinam e se superpõem dependendo da ocasião, gerando um terceiro espaço que é a tradução.

Imaginar a tradução como a ação de mestiçar-se, de carregar no próprio corpo duas ou mais culturas, torna a ação de levar um texto de uma língua/cultura, localizada num tempo e espaço geográficos, para outra língua/cultura, a própria transculturação. E não haveria de ser de outra forma: não é possível pensar a tradução, que ocorre antes de tudo dentro do tradutor, como uma transferência compartimentada. Pensar a tradução como inter ou multicultural talvez permitisse outra visão separatista de tradução, mas daí já nem seria tradução, mas uma espécie de ação dicionarizante, na qual se poderia ver de um lado uma palavra ou conceito e de outro seu possível significado na outra língua/cultura.

Mas é claro que não estou falando aqui apenas de tradução de palavras. Imagens, gestos e expressões humanas, ritos e expressões midiáticas em geral, 
cenários e panoramas também são traduzíveis e transitam entre línguas/culturas. Meu foco neste trabalho são as imagens estáticas produzidas por mãos humanas.

As imagens fazem parte da construção do conhecimento humano desde muito tempo. Começou, para nós ocidentais, nas cavernas de Lascaux, e continua até nossos dias, mas não sem muitas discussões sobre seu valor, algumas delas bem apaixonadas e que definiram os rumos da humanidade. Alain Besançon (1997) explica que nossa vontade de opor as imagens - sempre com menor valor - às letras e à escrita surgiu já nas raízes da formação greco-judaica de nossas sociedades ocidentais: a partir de Platão, as imagens feitas por homens passaram a ser consideradas cópias imperfeitas da realidade, que por sua vez era uma cópia imperfeita do mundo das ideias. Ou seja, as imagens eram imperfeitas duas vezes. Por outro lado, os judeus sempre tiveram uma veneração muito grande pelo verbo: até hoje não traduzem seus livros sagrados. E seu deus teria determinado em seu Segundo Mandamento que não se venerassem imagens.

Bruno Latour (2002) aprofunda a reflexão sobre o tabu do Segundo Mandamento na sociedade ocidental, que é essencialmente cristã: o grande problema seria, novamente, platônico. Se alguém cria uma imagem com suas próprias mãos, seja na religião, nas artes ou nas ciências, estará condenado a um impasse (double bind no original): ou a imagem foi uma criação exclusivamente sua e, portanto, carregada com seus vícios e cheia de seus defeitos, ou ela foi inspiração divina e, neste caso, a pessoa não passou de um canal de transmissão, não tendo mérito sobre a obra, mas ainda assim infectando-a com seus defeitos humanos. E tanto faz se a imagem é poderosa ou um fiasco.

Mas o fato é que as imagens atravessam os séculos transmitindo conhecimentos, formando percepções de mundo e transculturando aqueles que as recebem, apesar da prevalência da escrita e do desprezo latente pelas imagens. Um exemplo útil para este texto é trazido por Rogério de Campos (2015): ele fala dos bänkelsängers, pequenas trupes que, por volta do século XIV até o XVII, circulavam pelo que hoje é a Alemanha, contando histórias ao povo analfabeto, mas faziam isso usando ilustrações presas numa lona enquanto cantavam e apontavam com uma vareta para a cena correspondente à parte da história em cada momento. Temos neste exemplo não apenas o uso da imagem, mas também uma das formas precursoras das histórias em quadrinhos. E não só isso: Campos explica que os bänkelsängers também faziam críticas a pessoas (geralmente os nobres) e situações através de suas histórias quase sempre histórias sobre crimes ou sensacionalistas, mas havia aquelas ligadas a grandes personalidades da época -, de modo que eram também formadores de 
opinião pública. Ou seja, o que a população recebia eram histórias filtradas pelas lentes dos contadores.

Enviesar percepções de mundo com imagens não é exclusividade, porém, de contadores de histórias populares. Peter Burke (2004) lembra que os pintores, enquanto tradutores culturais que usam imagens em vez de palavras, sempre recorreram aos estereótipos para cativarem e convencerem seus públicos: temos casos de pintores europeus do século XVI representando os recém-descobertos ameríndios como canibais inveterados; também temos representações de irlandeses por pintores ingleses, no século XIX, desenhando-os com feições de macacos; e ainda temos diversos pintores alemães, franceses e italianos representando os povos que hoje habitam o Oriente Médio em situações e corpos estereotipados de acordo com o que até hoje vive no imaginário ocidental: odaliscas, haréns, banhos, escravos, eunucos, luxúria, preguiça, etc. As imagens tornam-se agentes poderosos nesse último caso para perpetuar uma visão de mundo que até hoje prejudica os estereotipados.

\section{0 MUNDO ÁRABE TRADUZIDO EM QUADRINHOS: $H A B I B I$}

A ideia de um Oriente exótico e atrasado acompanha o Ocidente há vários séculos, desde que o Islamismo ganhou vastos territórios no norte da África, na Península Arábica e em outros pontos da Ásia próximos da Europa - toda essa região foi nomeada com o termo genérico Oriente Médio. Em sua famosíssima obra, Said (2003b) cunha o termo orientalismo para explicar esse fenômeno que nada mais faz do que diminuir o valor e as aspirações dos falantes de árabe e/ou residentes no Oriente Médio. Essa diminuição não acontece apenas nas artes, mas também em outros ramos do conhecimento e cultura humanos: artistas, cientistas e grandes líderes ocidentais constantemente constroem novas narrativas, obras de arte, artigos científicos e políticos etc., reafirmando a posição retrógrada dos orientais, além, é claro, de homogeneizar drasticamente a diversidade de culturas e pensamentos dos povos ditos orientais. Armênios, sírios, palestinos, turcos, persas, otomanos, berberes, egípcios, magrebinos, entre outros, tornam-se todos uma coisa só: pessoas vestindo longas túnicas e usando pedaços de pano nas cabeças, de modo a cobrir quase todo o corpo, além de camelos por toda parte e cenários das mil e uma noites. ${ }^{4}$

4. A única exceção é o povo judeu, que conseguiu se diferenciar desse estereótipo apesar de viver no território do Oriente Médio. As razões disso vão muito além de questões "meramente" culturais, mas não é objetivo deste texto discutir essa diferenciação. 
O orientalismo é uma forma de racismo e chega até a incutir no imaginário ocidental a ideia de que os povos do Oriente Médio não seriam capazes de desenvolver filosofias ou raciocínios mais abstratos e sofisticados que os dos europeus. Num primeiro momento, esse orientalismo afetou os europeus em geral, mas a partir da segunda metade do século XX, mais especificamente depois da Guerra dos Seis Dias, serão os norte-americanos quem mais explorarão os estereótipos orientalistas, especialmente em sua guerra fria contra a antiga União Soviética e na busca pelo controle do comércio do petróleo no mundo.

Falando agora sobre quadrinhos, uma importante característica deles é a capacidade de nos mostrar representações de corpos humanos e cenários e nos fazer evocar sentidos através disso. Para isso acontecer, foi preciso um longo caminho de aprendizagem, repetição e reconhecimento. Aprender a extrair informações e sentidos de quadrinhos é tão complexo quanto aprender a ler uma língua verbal escrita. Neil Cohn (2013) explica que os quadrinhos não devem ser enxergados como produtos culturais que emprestam de outros sistemas semióticos algumas características e capacidades. Os quadrinhos, pelo contrário, são produtos finais de línguas visuais subjacentes a eles, com mecanismos, padrões, vocabulário e gramática próprios. Ou seja, as histórias em quadrinhos do Super-homem estão para a língua visual dos quadrinhos norte-americanos assim como Dom Casmurro está para a língua portuguesa escrita. Enxergar os quadrinhos como língua permite ampliar sobremaneira seus usos e potencialidades comunicativas. E também amplia a possibilidade de os quadrinhos serem traduzidos entre línguas/culturas, mas agora pensando-se não apenas nos elementos verbais, mas também nos elementos quadrinísticos, inerentes a esse sistema semiótico, nas representações de lugares e de pessoas e animais. Veremos isso acontecendo mais à frente.

Se lá atrás os imigrantes eram traduções transculturais ao vivo, andando por cenários e ocupando espaços inicialmente não feitos para eles, e com isso causando reações e percepções nem sempre amistosas nos ditos nativos - nativos apenas de corpo, lembremos sempre disso - nos quadrinhos as representações dessas traduções transculturais, tanto de corpos como de cenários, é bem aceita, já que sem riscos, mas ainda assim sujeita a crivos bem subjetivos, como os estereótipos e visões de mundo distorcidas. Lembremos que as imagens não são universais, elas variam de lugar e cultura para lugar e cultura, mas, mais do que isso, como nos faz recordar José Yuste Frias (2013), acreditar na universalidade das imagens e que seja possível transferi-las sem alterações entre povos e culturas diferentes é algo perigoso e contraproducente. 
Juntando as ideias agora, muitos quadrinhos ocidentais que representam os povos do Oriente Médio inevitavelmente acabam contaminados pelo orientalismo. Este torna-se um filtro pelo qual os ocidentais são levados a enxergar os corpos e cenários dos diversos povos habitantes do Oriente Médio, de modo que o que ocorre é uma tradução transcultural enviesada. ${ }^{5} \mathrm{O}$ caso que analiso a partir de agora é a obra Habibi, do quadrinista norte-americano Craig Thompson (2011a, 2012), e publicada originalmente em inglês nos Estados Unidos. A graphic novel conta a história de amor vivida entre os dois personagens principais. Inicialmente, a ainda criança Dodola é vendida pelos pais para um escriba, que se torna seu marido. Pouco tempo depois, o marido de Dodola é assassinado por bandidos usando turbantes e depois é levada por eles para um mercado de escravos. Ali, Dodola encontra Zam, um bebê que acabara de ser abandonado pela mãe, também escrava, para morrer. Dodola decide cuidar de Zam e consegue fugir do mercado de escravos rumo à imensidão do deserto. Lá, os dois personagens encontram um barco abandonado que lhes serve de refúgio, e ali sobrevivem por anos com o que conseguem obter do local e de caravanas que passam pela região, e com cujos homens Dodola negocia seu corpo em troca de alimentos. Um dia, porém, Dodola é novamente sequestrada e vai parar no harém do sultão da região, na moderna cidade de Vanatólia, e assim os dois personagens ficam separados por anos, com Zam sobrevivendo como pode sem Dodola. Depois de muitas reviravoltas, Zam se torna um eunuco no palácio do sultão e reencontra Dodola. Mais uma vez, os dois conseguem fugir e outras reviravoltas acontecem.

Habibi não é uma obra qualquer. Logo que foi lançada, Thompson (2011b) explicou numa entrevista que o evento do Onze de Setembro nos Estados Unidos foi o mote para sua criação. A islamofobia e o medo de atos terroristas havia aumentado consideravelmente, mas Thompson queria mostrar a beleza do Islã e como os muçulmanos tinham muito mais semelhanças que diferenças com os cristãos norteamericanos. Assim, ele estudou a cultura árabe e rudimentos do alfabeto e iniciou sua criação. Em várias páginas há representações artísticas da escrita árabe e dos famosos arabescos. Também a obra conta com outras histórias, de personagens bíblicos do Alcorão ou do Hádice, ${ }^{6}$ que são contadas em quadrinhos paralelamente às

5. É claro que existem exceções, e uma das mais marcantes é Palestine, de Joe Sacco (2003). Inicialmente publicada em nove edições, entre 1993 e 1995, a graphic novel ganhou uma versão em volume único em 2001, com prefácio do próprio Edward Said, que elogia o modo com a obra de Sacco não repete a visão romântica de harmonia e democracia buscada pelo povo de Israel e desejada passivamente pelo povo palestino.

6. O Hádice é um conjunto de histórias e leis relacionadas principalmente à figura do fundador do Islã, Maomé. 
aventuras de Dodola e Zam. A obra tem um nível de detalhamento impressionante e foi reconhecida por isso: Habibi ganhou um prêmio Eisner (considerado o Oscar dos quadrinhos) e o prêmio BD Virgin, no tradicional Festival de Angoulême, na França.

Aprofundando mais a análise da obra, Nadim Damluji (2011) mostra que a apreensão da escrita árabe e das histórias e lendas ligadas ao Islã pelo quadrinista é louvável e demonstra que ele realmente pesquisou, aprendeu e até compreendeu parte da cultura islâmica, e só por isso a obra já vale ser lida. O problema acontece justamente na representação dos personagens e dos cenários: seguindo a tradição orientalista europeia, os personagens secundários são extremamente sexualizados e/ou submissos quando mulheres, ou extremamente violentos, lascivos e/ou preguiçosos quando homens. Quando se trata dos personagens principais, a coisa só piora: Dodola, que representa uma mulher árabe na história, é o tempo todo sexualizada, aparecendo várias vezes sem roupas e quase sempre sendo estuprada por algum homem - para conseguir comida ou pela simples imposição deles. Mesmo quando representada como criança ela sofre abusos. Mas o pior para Damluji é a parte final do livro, em que somos apresentados à cidade de Vanatólia e percebemos que é uma cidade moderna, com cartazes que lembram logos como o da Coca-Cola, carros tipo SUV circulando e mulheres livres empurrando modernos carrinhos de bebê. Ou seja, Vanatólia poderia representar tranquilamente uma moderna metrópole ocidental. Para Damluji, Thompson localiza a história de Habibi no tempo e no espaço, e aproxima-a muito mais de nós, de modo que o que ele faz é novamente representar os povos do Oriente Médio com os estereótipos retrógrados do orientalismo...

Quando foi traduzida no Brasil pelo tradutor Érico Assis (THOMPSON, 2012), e seguindo a tradição das traduções de quadrinhos em nosso país, apenas os elementos verbais em inglês foram modificados. Dentro dos balões houve o cuidado com o letreiramento, ${ }^{7}$ de modo a mantê-lo semelhante ao usado no original. As imagens fora dos balões e os escritos em árabe, porém, permaneceram as mesmas. Assim, nós brasileiros temos acesso às mesmas representações de cenários e corpos que os norte-americanos tiveram e, graças à nossa tradição de consumo excessivo de cultura de entretenimento norte-americana, ${ }^{8}$ é inevitável que tenhamos praticamente

7. Letreiramento é a forma artística aplicada às letras nos quadrinhos. O letreiramento ajuda, em alguns casos, a transmitir informações paralelamente às palavras. Personagens gritando, por exemplo, terão as letras de seus balões grandes e em negrito.

8. Só para citar dois exemplos: toda semana há novos filmes norte-americanos, legendados ou dublados, passando nos cinemas brasileiros, assim como toda semana há novos títulos de filmes, séries e documentários norte-americanos, também dublados ou legendados, na plataforma de streaming Netflix. 
os mesmo referenciais, estereótipos, preconceitos e percepções de mundo sobre os povos do Oriente Médio que os habitantes dos Estados Unidos têm. Fica patente que absorvemos o orientalismo de Habibi e somos levados a acreditar que o Oriente Médio seja um imenso deserto com camelos e caravanas, homens violentos trajando túnicas brancas e gutras ou turbantes nas cabeças, mulheres submissas e escravas trajando túnicas coloridas e bijabs ou chadores, e chefes de estado preguiçosos e déspotas, muito mais preocupados em satisfazer suas necessidades sexuais. Apenas para sentirmos o quão devastador isso é para nossa percepção dos mundos do Oriente Médio, lembremos que nós brasileiros também somos estereotipados pelos norte-americanos, com muitos deles acreditando que o Brasil se resume ao Rio de Janeiro e à Floresta Amazônica. ${ }^{9}$

\section{PODERIA SER DE OUTRA FORMA?}

É possível retirar o orientalismo de Habibi? Infelizmente não. O próprio Thompson (2011c), conversando posteriormente com Damluji, confirma que a graphic novel é cheia de personagens estereotipados, que muitos dos cenários foram criados pensando na famosa obra The Arabian nigbts de Richard Burton, e que ele realmente usou e abusou da sexualidade de Dodola. Tentar usar o interior dos balões e legendas para dirimir em parte a percepção orientalista não é uma opção: seria totalmente incoerente se houvesse uma vinheta representando dois corpos humanos nus, com o homem forçando o sexo e a mulher protestando (Thompson é realmente um artista ao exprimir feições e gestos que representam visualmente um estupro) enquanto nos balões haveria frases do tipo "te desejo e não posso resistir ao teu charme" ou "apenas tenha cuidado com meu corpo". Um prefácio talvez ajudasse, mas devemos lembrar que a grande maioria de outras obras que expressam o orientalismo não contêm avisos dizendo que são orientalistas, de modo que um prefácio desses causaria mais espanto que conscientização: muitos leitores se perguntariam como Habibi pode ser uma obra de ficção se ela representa "exatamente" a realidade dos árabes e muçulmanos que é mostrada em tantas outras obras. Notas de rodapé estão fora de questão, já que tal recurso raramente é usado em quadrinhos.

9. É famoso o $15^{\circ}$ episódio da $13^{\mathrm{a}}$ temporada da série animada norte-americana Os Simpsons (título Blame it on Lisa), em que a família amarela vem para o Brasil, e aqui encontra mulatas dançando samba e macacos correndo pelas ruas, todo mundo falando espanhol, violência generalizada e o Cristo Redentor muitíssimo próximo do Rio Amazonas. 
Mas traduzir implica um dever ético. Tal como na fala de Elisabetta Bartuli, que epigrafa este trabalho, Andrew Chesterman (2001) defende que o tradutor deve trabalhar com a ética do compromisso, apoiando-se nas virtudes da veracidade, da justiça, da confiabilidade, da determinação, da empatia, entre outras qualidades, tudo para manter o esforço de traduzir bem e com justiça. Também defendo que a pessoa que traduz tem a obrigação de realizar seu trabalho respeitando ao máximo as características de uma língua/cultura, especialmente se ao traduzir corre-se o risco de rotular de forma negativa os povos detentores dessa língua/cultura. Se não foi possível ao tradutor brasileiro escapar do orientalismo inerente à obra, podemos pensar no trabalho sobre as imagens como uma forma alternativa de diminuir essa ideologia. E isso não é algo intangível: Yuste Frias (2011) defende que o tradutor deve ter poder para trabalhar os paratextos, os elementos (verbais ou não verbais) que apresentam, introduzem, acompanham, rodeiam envolvem e ilustram os textos verbais. E é isso que ele põe em prática nas traduções que faz.

Assim, proponho duas pequenas traduções ao texto de Habibi, dois acréscimos de imagens na versão brasileira. O objetivo é aproximar ainda mais a obra da realidade ocidental, de modo a fazer dela uma hipérbole do orientalismo - um exagero de realidade tão grande que faça o leitor chegar ao final e pensar que claramente leu uma obra de ficção, que nada tem a ver com a realidade de qualquer povo atual.

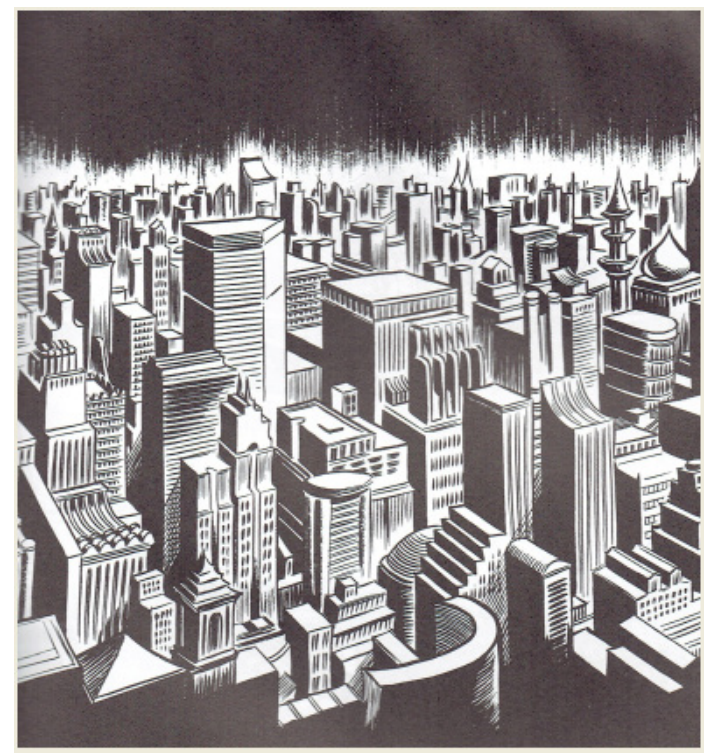

Figura 1. A metrópole de Vanatólia.

Fonte: Thompson (2011, p. 539).

Como dito anteriormente, Damjuli (2011) fala que Vanatólia é o grande problema de Habibi, por apresentar uma metrópole oriental moderna e perigosamente familiar. Mas podemos perceber na Figura 1 que há duas características da cidade que a tornam significativamente diferente das metrópoles ocidentais: primeiro, as cimeiras dos prédios, algumas em nada semelhantes a qualquer coisa vista nas cidades ocidentais - até aí tudo bem, já que estamos falando de outra cultura, com outros valores estéticos; segundo, não há torres de antenas de celular sobre os prédios, o que implica 
imaginar que não haja comunicação celular nesse lugar - de fato, ao longo de todas as cenas que representam a cidade ou seus habitantes, não há qualquer referência à comunicação via celular. Ora, se Vanatólia é uma metrópole moderna, com muitas pessoas vestidas à moda ocidental e seguras em andar nas ruas (Fig. 2), com arranhacéus e problemas de excesso de lixo e poluição, por que não haveria celulares? Seria mais uma forma de mostrar que essa modernidade de Vanatólia seria apenas aparente, que no fundo seu povo seria avesso a certas tecnologias, por não aceitá-las ou por simplesmente não compreendê-las? Seja qual for o motivo que levou Thompson a não incluir celulares em Vanatólia, o discurso orientalista se reforça mais uma vez. Recordando o estereótipo do Oriente Médio ligado às mil e uma noites, até faz sentido pensar que não haja celulares: eles não funcionariam nas imensidões de deserto que cercam a cidade e talvez nem poderiam se comunicar com o restante do mundo globalizado.

neste $\quad \begin{array}{r}\text { lembrar } \\ \text { momento }\end{array}$
que a tecnologia de t e l e c o mun i c a çã o móvel já existe há mais de setenta anos, mas sua difusão para uso comercial só começou na década de 1980, sendo que no Brasil as primeiras antenas de telefonia celular apareceram na década de 1990. Nas últimas décadas, a tecnologia se desenvolveu muito, com os aparelhos celulares

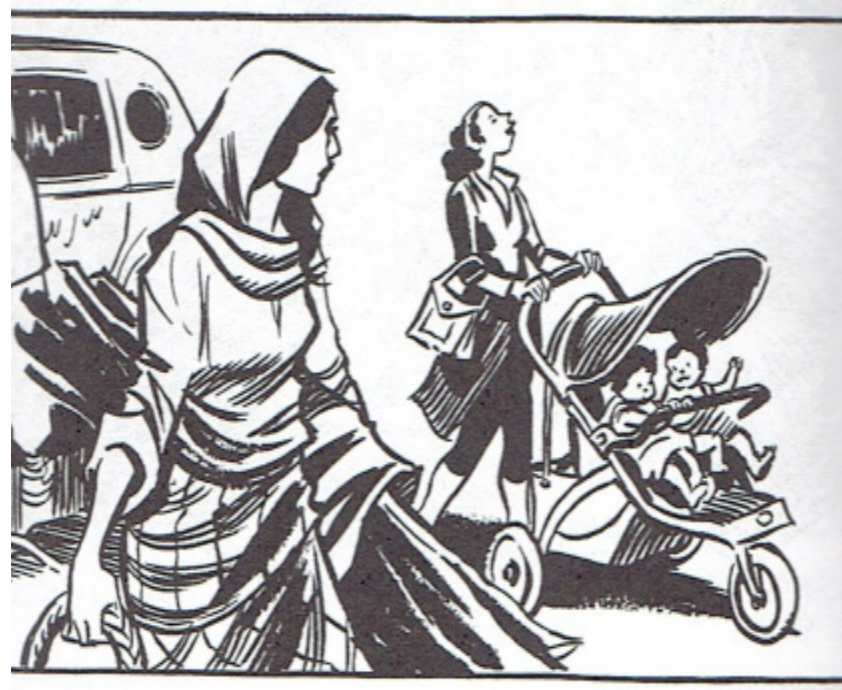

Figura 2. Dodola observa as pessoas despreocupadas.

Fonte: Thompson (2011, p. 556).

atuais sendo capazes de não apenas fazerem chamadas telefônicas, mas também acessarem a internet, tirarem fotos, entre diversos outros recursos. Em 2011, quando Habibi foi lançado, já havia inclusive os modelos de celulares touch screen, tão usuais em nosso dias. Além disso, a difusão da tecnologia tornou-a barata e acessível para a maioria da população mundial. É praticamente impossível encontrar algum povo da atualidade que não saiba o que é um celular, e isso vale também para os 
diversos povos do Oriente Médio que, em maior ou menor grau, conhecem e/ou compram e utilizam aparelhos celulares.

Sobre a questão ambiental, em diversos trechos de Habibi vemos representações de depredação de recursos naturais, poluição da água e lixões a céu aberto. O povo de Vanatólia, além de preguiçoso, violento e sexualizado, não tem consciência ambiental e destrói os recursos naturais e as paisagens. Isso é feito para diminuir ainda mais os povos do Oriente Médio? Talvez. Ou talvez seja uma jogada do autor para aumentar a consciência do próprio povo norte-americano sobre o assunto. ${ }^{10}$ Mas tal aspecto também mostra que Vanatólia se assemelha demais às modernas metrópoles ocidentais.

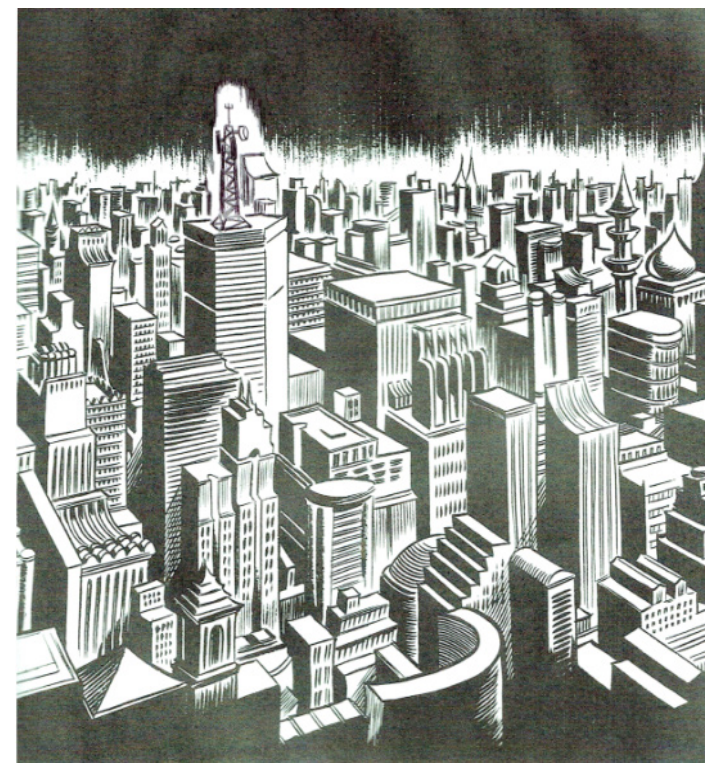

Figura 3. Modernizando ainda mais Vanatólia.

As traduções que proponho aparecem nas figuras a seguir. $\mathrm{Na}$ primeira, uma mudança no cenário: acrescentei à imagem da Figura 1 uma torre com três antenas, duas direcionais e uma parabólica, ambas empregadas pelas atuais empresas de telefonia móvel na distribuição dos sinais dos diversos telefones celulares, sobre o topo de um dos prédios, mas de modo a ficar bem visível para o leitor, conforme a Figura 3. O processo de recriação da página foi feito à mão, usando folha sulfite, lápis preto, caneta preta, régua e um bom editor de imagens no final.

10. Devemos lembrar que a ideia de conscientização ambiental ainda é muito recente, especialmente nos Estados Unidos. Apesar de a famosa Conferência Rio-92 sobre o meio ambiente ter acontecido quase 20 anos antes do lançamento de Habibi, o também famoso documentário Uma verdade inconveniente, com o ex-vice-presidente Al Gore, estreou apenas em 2006. Já um estudo mais recente, da organização Policy Interactive feito em 2014, mostra que os norte-americanos tendiam a achar que compartilhar carona, ferramentas e outros objetos era a melhor forma de diminuir o impacto no meio ambiente. Ainda nem se pensava em redução, reuso e reciclagem de lixo e embalagens. O estudo pode ser visto em https://newdream.org/resources/poll-2014, acesso em 05/06/2020. 
A segunda tradução, uma mudança nos corpos, é mostrada na Figura 4: na versão original, que vimos na Figura 2, Dodola observa uma mulher passeando enquanto empurra um carrinho com dois bebês. Para empurrar o carrinho, a mulher usa as duas mãos. Na nova versão, vista na Figura 4, a mulher agora empurra o carrinho com a mão direita enquanto segura um celular com a mão esquerda. Não dá para ver com toda certeza que há um celular na mão da mulher, devido ao tamanho da imagem e ao próprio rosto da mulher na frente do objeto, mas percebese que ela segura algo e, principalmente, o gesto de segurar um celular atualmente é perfeitamente reconhecível por qualquer brasileiro que já tenha visto alguém manuseando um aparelho desses. ${ }^{11}$ Aqui o mesmo processo de recriação foi usado para incluir a imagem na Figura 4.

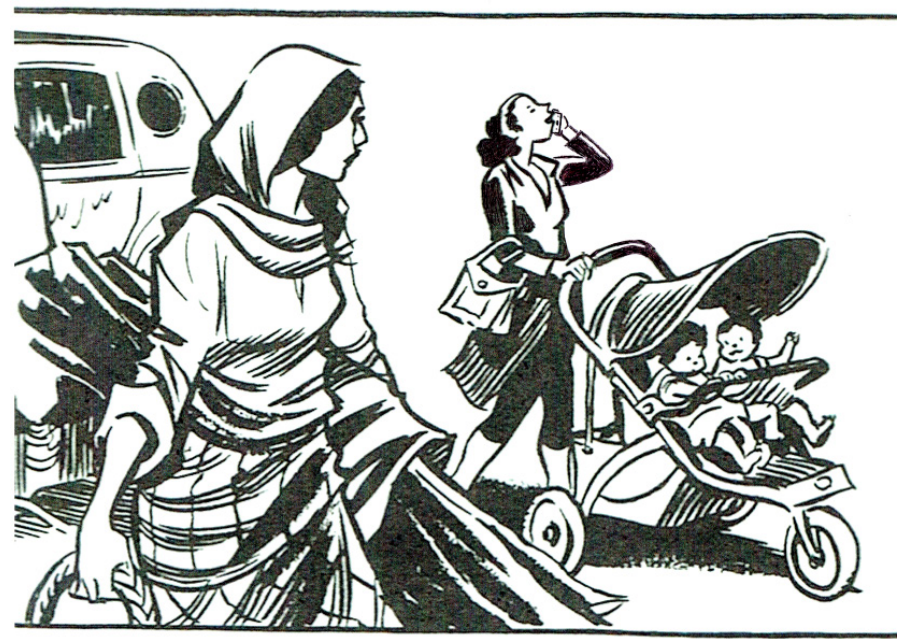

Figura 4. 0 gesto "universal" de segurar e falar com um telefone celular. Fonte: Autoria própria.

Com esses dois acréscimos busquei tornar o mundo fictício de Habibi ainda mais próximo dos mundos ocidentais, como forma mesmo de chocar o leitor: um mundo moderno, com acesso a tecnologias de ponta e problemas ambientais, claramente não pode admitir pessoas sendo vendidas e escravizadas, governadores lascivos, carrascos, guardas de palácio carregando lanças ao invés de revólveres e haréns lotados de mulheres escravas sexuais. Outras intervenções desse tipo, sobre os corpos e cenários, podem ser feitas ao longo da obra - menos, é claro,

11. Modificar a mão direita da mulher, para deixar o celular mais visível, implicaria modificar a bolsa e boa parte do corpo, mas minha capacidade de desenho ainda não é tão acurada. 
nas partes ligadas às histórias e lendas islâmicas. No final, teríamos uma obra com tantos aspectos semelhantes à realidade brasileira, mas ao mesmo tempo com tantas diferenças bizarras, que seria imprudente admitir que tal mundo pudesse fazer parte de qualquer povo deste planeta.

\section{CONCLUSÕES}

Ver um corpo usando determinadas peças de roupa e/ou adereços que não os que consideramos habituais em nossas esferas socioculturais nos causa estranhamento. E quanto mais estranhas forem as vestimentas, mais exótico será o ser humano que as veste, mais estrangeirizante será nossa percepção sobre tal ser humano. Isso vale para qualquer pessoa dentro de determinada cultura/povo, e também vale para representações da pessoa, seja em fotos ou desenhos. Nossa curiosidade pode até ajudar para que nos aproximemos desse ser diferente, mas isso não necessariamente significará uma boa recepção... Apesar de eu ter tentado expressar neste trabalho que somos seres transculturais $e$ mestiços no modo como nossos corpos se apresentam aos outros - tanto próximos como distantes -, não há garantias de que esses outros compreenderão essa transculturalidade e mestiçagem da forma como desejamos.

Como tradutor e também pessoa mestiça, portador de diversas culturas, todas igualmente válidas e valorizadas, o que me resta é tentar mostrar que ser diferente não implica hierarquia de valores e culturas. Isso passa não apenas pelas palavras que uso para traduzir outras culturas e povos, mas também pelas imagens que passam por minhas mãos. Mesmo que eu não consiga mudar as imagens, como foi a proposta final neste texto, posso ao menos tentar explicá-las de outro modo com minhas palavras, evitando, ou tentando evitar, que tais imagens diminuam os seres que elas representam. Claro que há questões mercadológicas e editoriais atravessando a grande maioria das traduções, e mudar imagens pode ser um passo enorme ainda a ser conquistado na tradução em geral, mas é possível e pode ser tentado.

Espero ter demonstrado que o orientalismo, com toda sua carga pejorativa, pode ser conscientemente contestado na tradução, levando o leitor da obra traduzida - seja esta qual for, e obviamente incluindo os quadrinhos - a perceber e compreender que sempre haverá questões sociopolíticas e culturais enviesando tanto a obra em si quanto as leituras possíveis dela, mas que é possível sim perceber o mundo subjacente à obra, com seus corpos e cenários, sem estragá-lo. 


\section{REFERÊNCIAS}

BAUMAN, Zygmunt. (1998). O mal-estar da pós-modernidade. Tradução de Mauro Gama e Cláudia Martinelli Gama. Rio de Janeiro: Jorge Zahar Editor.

BESANÇON, Alain. (1997). A imagem proibida: uma história intelectual da iconoclastia. Tradução de Carlos Sussekind. Rio de Janeiro: Bertrand Brasil.

BLOMMAERT, Jan; VERSCHUEREN, Jef. (2002). Homogeneism. In: Debating Diversity: analysing the discourse of tolerance. New York: Routledge.

BURKE, Peter. (2004). Estereótipos dos outros. In: Testemunba ocular: história e imagem. Tradução de Vera M. X. dos Santos. Bauru, SP: EDUSC, p. 153-174.

CAMPOS, Rogério de. (2015). Imageria: o nascimento das histórias em quadrinhos. São Paulo: Veneta.

CHESTERMAN, Andrew. (2001). Proposal for a Hieronymic Oath. The Translator, v. 7, n. 2, p. 139-154.

COHN, Neil. (2013) The visual language of comics: Introduction to the structure and cognition of sequencial images. London: Bloomsbury.

DAMLUJI, Nadim. (2020). Can the Subaltern Draw? The Spectre of Orientalism in Craig Thompson's Habibi. The Hooded Utilitarian. 05/10/2011. Disponível em https://www. hoodedutilitarian.com/2011/10/can-the-subaltern-draw-the-spectre-of-orientalismin-craig-thompsons-habibi/ Acesso em 05/06/2020.

LAPLANTINE, François; NOUSS, Alexis. (1997). Le métissage - un exposé pour comprendre, um essai pour réfléchir. Paris: Flammarion.

LAPLANTINE, François. (2005). Le social et le sensible - Introduction à une anthropologie modale. Paris: Téraèdre.

LATOUR, Bruno. (2002). What is iconoclash? Or is there a world beyond the image wars? In Latour, B; Weibel, P. (eds). Iconoclash - Beyond the image wars in science, religion and art. Karlsruhe, Germany: ZKM, p. 15-38.

MALUF, Sonia W. (2001). Corpo e corporalidade nas culturas contemporâneas: abordagens antropológicas. Esboços, v. 9, n. 9, Florianópolis, p. 87-101. Disponível em: http:// portfolio.unisinos.br/OA12/pdf/sonia_maluf_artigo.pdf Acesso em 05/06/2020 
NASH, Kieran. (2017). The difference between an expat and a immigrant? Semantics. BBC: Worklife. Disponível em https:/www.bbc.com/worklife/article/20170119-whoshould-be-called-an-expat Acesso em 05/06/2020.

NOUSS, Alexis. (2012). A tradução: no limiar. Tradução de Izabela Leal. Alea: Estudos Neolatinos. 14:1, Rio de Janeiro. p. 13-34, jan/jun 2012. Disponível em: http:// dx.doi.org/10.1590/S1517-106X2012000100002. Acesso em 21/02/2017

SACCO, Joe. (2003). Palestine. Seattle: Fantagraphics Books.

SAID. Edward. (2003a). Reflexões sobre o exílio. In Reflexões sobre o exílio e outros ensaios. Tradução de Pedro M. Soares. São Paulo: Cia das Letras. p. 46-60.

SAID. Edward. (2003b). Orientalism. London: Penguin Books.

THOMPSON, Craig. (2011a). Habibi. New York: Pantheon.

THOMPSON, Craig. (2011b). Craig Thompson: fundamentals. [Entrevista concedida a] Meakin Armstrong. Guernica. 15/09/2011. Disponível em https://www.guernicamag. com/thompson_interview_9_15_11/ Acesso em 05/06/2020.

THOMPSON, Craig. (2011c). A Conversation about Habibi’s Orientalism with Craig Thompson. [Entrevista concedida a] Nadim Damluji. The Hooded Utilitarian. 16/11/2011. Disponível em https://www.hoodedutilitarian.com/ 2011/11/a-conversation-abouthabibis-orientalism-with-craig-thompson/ Acesso em 05/06/2020.

THOMPSON, Craig. (2012). Habibi. Tradução Érico Assis. São Paulo. Quadrinhos na Cia.

TOLEDO, Leonardo. (2015). A formação da identidade transcultural, a exemplo de Rafik Schami. Mutatis Mutandis - Traducción, género e identidad, v. 8, n. 2, p. 466-484.

TRADURRE. (2008). Direção de Pier Paolo Glarolo. Itália: Jolefilm. Disponível em https:// www.youtube.com/watch?v=JCLoKrZbkxk Acesso em 05/06/2020.

WELSCH, Wolfgang. (2010). Was ist eigentlich Transkulturalität? In Darowska, L.; Lüttenberg, T.; Machold, C. (eds). Hocbscbule als transkultureller Raum? Beiträge zur Kultur, Bildung und Differenz. Bielefeld, Deutshland: Transcript, p. 39-66.

YUSTE FRÍAS, José. (2011). Leer e interpretar la imagen para traducir. Trab. Ling. Aplic, v. 50, n. 2, Campinas, p. 257-280. 
YUSTE FRÍAS, José. (2013). Nuevas perspectivas para traducir la imagen em publicidade internacional. In DOMÍNGUEZ. Xoán M (ed). In Traducción para la comunicacion internacional. Granada: Editorial Comares, p. 83-92.

Recebido: 16/6/2020

Aceito: 16/7/2020

Publicado: 31/7/2020 